\title{
Cocktail of chelated minerals and phytogenic feed additives in the poultry industry: A review
}

\author{
Vishwanath Gopal Bhagwat(iD, Ellusamy Balamurugan (D) and Paramesh Rangesh (D) \\ The Himalaya Drug Company, Makali, Bengaluru, Karnataka, India. \\ Corresponding author: Vishwanath Gopal Bhagwat, e-mail: dr.bhagwat@himalayawellness.com \\ Co-authors: EB: dr.balamurugan@himalayawellness.com, PR: dr.rangesh@himalayawellness.com \\ Received: 11-09-2020, Accepted: 30-12-2020, Published online: 09-02-2021
}

doi: www.doi.org/10.14202/vetworld.2021.364-371 How to cite this article: Bhagwat VG, Balamurugan $E$, Rangesh $P$ (2021) Cocktail of chelated minerals and phytogenic feed additives in the poultry industry: A review, Veterinary World, 14(2): 364-371.

\begin{abstract}
This review article delineates the role of chelated minerals and phytogenic feed additives (PFAs) cocktail supplementation in improving the overall health status and production performance of poultry birds and its economic effects in the poultry industry. Organically complexed minerals have many advantages over inorganic sources. It has improved absorption and efficacy, which meets the bird's requirements comfortably with a low-dose level. Hence, inorganic forms can be replaced with lower-dose levels of organic minerals without any adverse effects on production performances in broilers and layers. PFAs possess medicinal properties, such as antimicrobial, antioxidant, adaptogenic, and immunomodulatory, therefore, could be recommended as supplements. They are also growth promoters that enhance the overall health status and augment poultry birds' production performance. Furthermore, the tremendous potential of PFAs could be extracted with the recent advances in science and technology. With the advantages of organically complexed minerals and multiple beneficial applications, there is a resurgence to develop PFAs as a cocktail of organic minerals to improve the overall health status of poultry birds and augment their productivity, which, in turn, helps the poultry industry to grow decisively and economically.
\end{abstract}

Keywords: chelated, cocktail, inorganic, organic, phytogenic feed additives, poultry, production performance, supplement, trace minerals.

\section{Introduction}

Minerals are vital for physical and mental well-being. They are components of all cells, including the blood, hormones, nerves, muscles, bones, teeth, and soft tissue. Some minerals are integral components of enzymes that catalyze biochemical reactions, including energy production, metabolism, nerve-impulse transmission, muscle contraction, and cell permeability. It is a well-known fact that in commercial poultry feed, the inorganic form of trace minerals is added (sulfate or oxide salts) at up to ten-fold higher dose than the National Research Council's (NRC, USA) recommendations because of its low retention rates [1-3]. The excretion of unabsorbed inorganic trace minerals leads to environmental contamination [4]. Organic trace minerals have higher bioavailability than inorganic trace minerals. Hence, supplementation of organically complexed/chelated trace minerals could help avoid the use of higher dosages of inorganic trace minerals in poultry feed and could prevent environmental contamination because they have lower inclusion rates and reduced excretion $[5,6]$.

Chelated complexes of minerals contain a central atom along with a ligand (proteins, carbohydrates,

Copyright: Bhagwat, et al. Open Access. This article is distributed under the terms of the Creative Commons Attribution 4.0 International License (http://creativecommons.org/licenses/ by/4.0/), which permits unrestricted use, distribution, and reproduction in any medium, provided you give appropriate credit to the original author(s) and the source, provide a link to the Creative Commons license, and indicate if changes were made. The Creative Commons Public Domain Dedication waiver (http:// creativecommons.org/publicdomain/zero/1.0/) applies to the data made available in this article, unless otherwise stated. lipids, or amino acids) containing a minimum of one ligand atom (sulfur, oxygen, or nitrogen) with a pair of free electrons. The ligand atom is bound with the metal atom by a coordinate bond by donating an electron pair from the ligand to the electron acceptor [7].

The inclusion of low organic mineral levels has been widely practiced due to their physiologic contributions (Figure-1) [8].

There are two main disadvantages of using inorganic trace minerals in the poultry diet. First, the contamination factor: Copper sulfate and zinc oxide are common inorganic sources of copper and zinc used in the poultry diet, but these two sources are derived from the steel industry and have a large number of contaminants, such as fluorine and cadmium, which get transferred into the poultry diet [9]. Second, the antagonistic effects between inorganic trace minerals could decline its metabolism and absorption rate. Chelate complexes of metals with amino acids are inert because of the ionic and covalent bonding between the ligand and mineral. Thus, these forms remain unaffected by the factors that lead to precipitation, similar to how it happens to inorganic minerals after the solubilization of salt [6]. Furthermore, the size and stability of improvement due to chelation of trace minerals could protect the trace minerals, while passing through the gastrointestinal tract and are absorbed in its intact form, without any degeneration of the amino acids [5].

The herbs and plant extracts used in animal feed are known as phytogenic feed additives (PFAs). They are of plant origin and are added to animal feed to enhance productivity by improving the digestibility, 


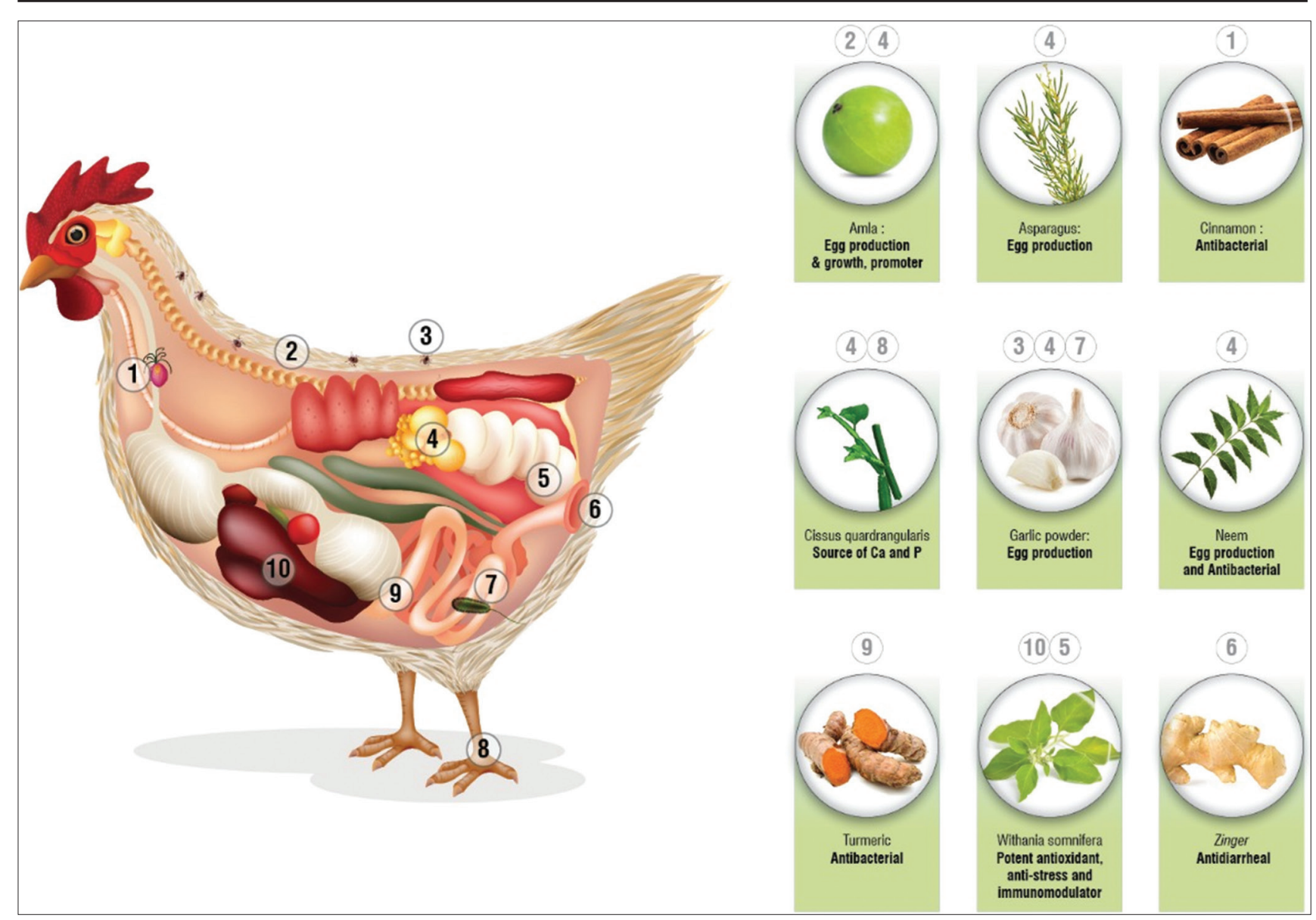

Figure-1: The beneficial application of herbs in poultry health and production. Source: Sheoran [8].

nutrient absorption, and elimination of pathogen residents in the animal gut [10-12]. Unlike ruminants, poultry does not have a natural bacterial flora capable of degrading all nutrients. Hence, the administration of antibiotic growth promoters (AGPs) is recommended to augment production performance and improve poultry birds' state of health as they have limited immunity against infection due to colonization by pathogenic microorganisms. However, the WHO observed that it is impossible to use AGPs that cause antimicrobial resistance in animals. The European Union banned the systemic use of AGPs in animal feed at the beginning of 2006. The removal of AGPs from the poultry diet has detrimental effects on production performance. Moreover, the removal of AGPs increases the regeneration of pathogens, leading to the decline of poultry animals' health status and causing economic losses to the poultry industry. Here, the addition of PFAs to poultry feed is suggested to improve the health status of animals and augment production performance [13].

This review article delineates the role of supplementing a cocktail of chelated minerals and PFAs in improving poultry birds' overall health status and productivity performance and its economic effects in the poultry industry.

\section{Mechanism of Absorption of Organic Minerals}

After the intake of organic minerals from the poultry diet, mineral absorption occurs in any intestine region; however, metals are absorbed in the duodenum. The inert mineral complexes undergo hydrolysis in the stomach and enter the intestine lumen, where the ligand-mineral bonding occurs. Transporter ligand safeguards mineral interactions with dietary antagonists, such as oxalic acid, phytic acid, and antinutritional factor gossypol. In the intestine, the ligand-mineral complexes become absorbed through cells of the intestinal lining. Inorganic minerals get excreted in the feces due to the non-availability of an inorganic metal transporter (Figure-2) [8].

\section{Importance of Using Organic Trace Minerals in Poultry}

Literature reports that the addition of chelated trace minerals in the poultry diet improves the performance parameters, bird health, and meat-quality traits. The performance of laying hen and eggshell quality improved following copper methionine supplementation compared with that of birds supplemented with copper sulfate [14]. Among chicks supplemented with chelated trace minerals, there was a significant increase in body weight gain, deposition of minerals in the tissue, and immunity and improved feed conversion ratio (FCR) compared with that among chicks supplemented with inorganic trace minerals at similar dose [15]. Broiler birds fed with a diet supplemented with organic chromium $(0.5 \mathrm{ppm})$ showed increased body weight gain compared with birds supplemented 


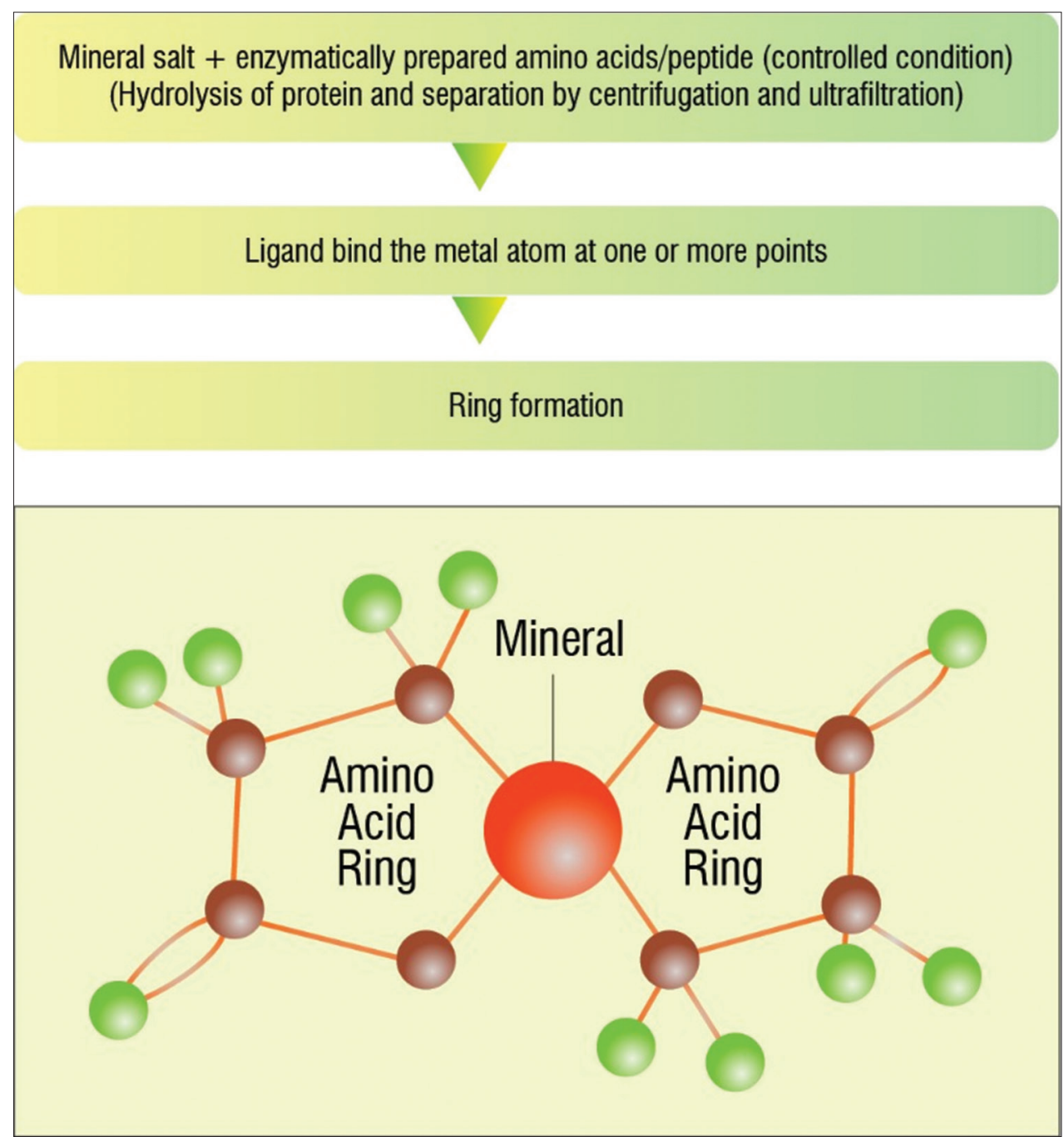

Figure-2: Chelated Mineral Preparation Techniques. Source: Sheoran [8].

with inorganic chromium sources [16]. There was an improved FCR in chicks fed a diet supplemented with organic sources of minerals compared with those fed with inorganic sources (1.63 vs. 1.74) [14]. In broiler fed mineral proteinate, ascites reduced from $5 \%$ to $2 \%$ [17]. Zinc/manganese methionine enhanced humoral and cell-mediated immune functions [18]. Hence, the chelated form is advantageous than the inorganic form.

Various research studies demonstrate that a dose of chelated minerals can be reduced in commercial broiler feed formulations without any negative effects on their production performance [5,19-21], antioxidant defense systems [22], hematological and biochemical parameters, and meat quality parameters [23]. Administration of chelated minerals at $25 \%$ of the NRC's standard recommendations has no detrimental effect on performance parameters, such as body weight gain and feed intake [24]. Supplementation of chelated trace minerals at $20 \%$ of inorganic trace minerals has no negative effect on body weight gain and FCR, with an advantage of a reduction in environmental contamination due to the lower excretion of minerals
[4]. Furthermore, literature reports revealed that the replacement of inorganic trace minerals with chelated minerals results in the augmentation of immunity parameters in chicks [25].

\section{The Effect of PFAs in Poultry}

The poultry industry has been the principal source to meet animal protein's global requirement among all other classes of livestock [26]. This can only be further strengthened by controlling infectious diseases as well as growth and production disturbances that would otherwise impose severe economic losses to the poultry sector. The emergence of new pathogens or variants of old pathogenic microorganisms can spread rapidly and affect the entire flock [26,27].

Since ancient times, plants and plant parts have a pivotal role as medicine sources for indigenous poultry production systems. The existing indigenous technical knowledge inherited from the past generations has sustained the local poultry production system $[28,29]$. Various researchers have explored indigenous medicinal herbs and plant extracts (e.g., garlic, cinnamon, tulasi, ginger, yucca, turmeric, neem, thyme, rosemary, and lemon) to enhance poultry health and augment the production performance with favorable 
results [30-35]. Moreover, a literature survey showed that dietary supplementation with herbal preparations positively affects performance parameters, such as body weight gain, feed intake, feed efficiency and carcass traits, biochemical parameters, and immune responses among poultry birds [36].

\section{Herbs as Growth Promoters for Poultry}

At present, there are many restrictions and bans on the use of various antibiotics and other medicinal products in the poultry diet because of the resultant bacterial resistance and possible transmission of antibiotic residues into the human food chain, which has been the utmost concern of poultry production [37,38]. In addition, the poultry feed industry is also confronting tremendous pressure from consumers to reduce AGPs addition in the poultry diet. A literature survey revealed that medicinal plants, plant extracts, and essential oils as PFAs in commercial broiler diet have beneficial effects on broiler performance parameters [39-42]. Furthermore, several authors have demonstrated that plant extracts and various phytobiotics originating from leaves, roots, tubers, herb fruit, spices, and other plants have shown the potential to enhance the production performances of poultry birds and thereby have proven their pivotal roles in strengthening the poultry industry $[43,44]$. These PFAs growth-enhancing effects could be attributed to the synergistic action of containing various active molecules and their potential to improve feed utilization efficiency [45].

\section{Herbs as Poultry Antioxidants}

At present, the preference for natural antioxidants in food has increased due to health benefits, such as preventing oxidative stress and diseases. Lipid peroxidation susceptibility of poultry meat due to polyunsaturated fatty acids drawback creates a huge demand for plant-based antioxidants [46]. Various plants possess excellent antioxidant properties, for example, rosemary (Rosmarinus officinalis), olive leaves (Olea europaea L.), garden thyme (Thymus vulgaris), marjoram (Origanum majorana), sage (Salvia officinalis), and oregano (Origanum vulgare) [47-51]. Furthermore, it has been demonstrated that tulasi (Ocimum sanctum) and Ashwagandha (Withania somnifera) possess excellent adaptogenic and antistress properties [52]. Apart from these, spices such as cinnamon, peppermint, marjoram, wild marjoram, cloves, caraway, and nutmeg have antioxidant properties as they contain compounds, such as polyphenols, flavonoids, and terpenoids [50-53].

\section{Effects of Herbs on Enzymes in Poultry}

Literature shows that supplementation of plant and plant extracts, as well as poultry diet, exerts positive and favorable influences on serum enzymes. Deshpande reported that tulasi leaf powder's dietary supplementation causes a significant increase in serum cholesterol and high-density lipoprotein levels in laying hens [54]. The addition of turmeric rhizome powder to the broiler diet considerably reduces liver enzyme levels, such as alkaline transaminase (ALT) and alkaline phosphatase (ALP) [55]. In contrast, the addition of tulasi leaf powder ameliorates the lead-induced toxicity in cockerels by reducing liver enzyme levels [56]. Feeding of tulasi leaf powder to broilers neutralizes aflatoxins toxic effects by significantly decreasing the enzyme activities of aspartate transaminase, ALT, and ALP [57]. Lanjewar et al. [58] reported that supplementation of tulasi leaf powder in broiler diet caused a significant reduction in serum low-density lipoprotein cholesterol, total cholesterol, and triglycerides.

Furthermore, Gupta and Charan [59] reported that tulasi supplementation reduces serum glutamic oxaloacetic transaminase (SGOT) levels in broilers. In contrast, it has no significant effect on serum glutamic pyruvic transaminase (SGPT), creatinine, and uric acid levels. Furthermore, supplementation with herbal growth promoters, such as amla to broilers, reduces cholesterol level, increases serum ALP, and SGPT levels and has no effect on SGOT levels [60]. Furthermore, feeding broilers with tulasi leaf powder $(0.5 \%)$ and selenium $(0.3 \mathrm{ppm})$ significantly decreased lipid peroxidation and increased plasma glutathione levels [61].

The beneficial applications, an overview of the usage of herbs, their modes of action for protecting poultry's health, and the production performance-enhancing effects are diagrammatically represented in Figure-3.

\section{Synergistic and Antagonistic Effects of PFAs in Poultry Industry}

The synergistic and antagonistic effects PFAs have been supported by various research studies reported in literature; Ren et al. [62] reported the synergistic beneficial impact of probiotics and phytobiotics. This study's findings revealed that combinations of probiotics and phytobiotics lead to a more enhanced functionality than their individual supplementation by reducing the survival of potentially problematic bacteria, such as ESBL-producing Escherichia coli on intestinal bacterial composition and their metabolic activity in young broilers [62]. Phytogenic compounds represent a promising alternative to antibiotics because they consist of many active ingredients. Upadhaya and Kim revealed that minor components present are critical to the PFA activity and may have a synergistic influence [63]. Several other researchers reported that polyphenol, flavonoids, and carotenoids present in herbs play a crucial role in PFAs synergistic effects by stimulating increased digestion in birds, resulting in the birds' enhanced growth [64-66]. Furthermore, literature reports reveal the synergistic and additive effects of the various molecules of the essential oils and their monoterpenoid components $[67,68]$.

Literature reports also revealed that the antagonistic effect has been attributed to the interaction between non-oxygenated and oxygenated 
Table-1: The Summary of synergistic and antagonistic properties of phytogenic feed additives.

\begin{tabular}{lll}
\hline Phytogenic feed additives & Effects & Reference \\
\hline Thymol/carvacrol & Synergistic & Pei et al., [74] \\
Thymol/eugenol & Synergistic & Pei et al, [74] \\
Carvacrol/eugenol & Antagonistic & Gallucci et al., [75] \\
Carvacrol/myrcene & Antagonistic & Gallucci et al., [75] \\
Cinnamaldehyde/Thymol & Synergistic & Pet al., [74] \\
Limonene/1,8-cineole & Synergistic & Tuuren and Viljoen [76] \\
a-pinene/Limonene & Synergistic & de Azeredo et al., [78] \\
Origanum vulgare/Rosmarinus Officinalis & Synergistic & Bassolé et al, [79] \\
Lippia multiflora/Mentha piperita & Synergistic & Fu et al, [80] \\
Syzygium aromaticum/Rosmarinus officinalis & Antagonistic & Bassolé et al., [81] \\
Cymbopogon citratus/ Cymbopogon giganteus & Synergistic & Synergistic \\
\hline
\end{tabular}

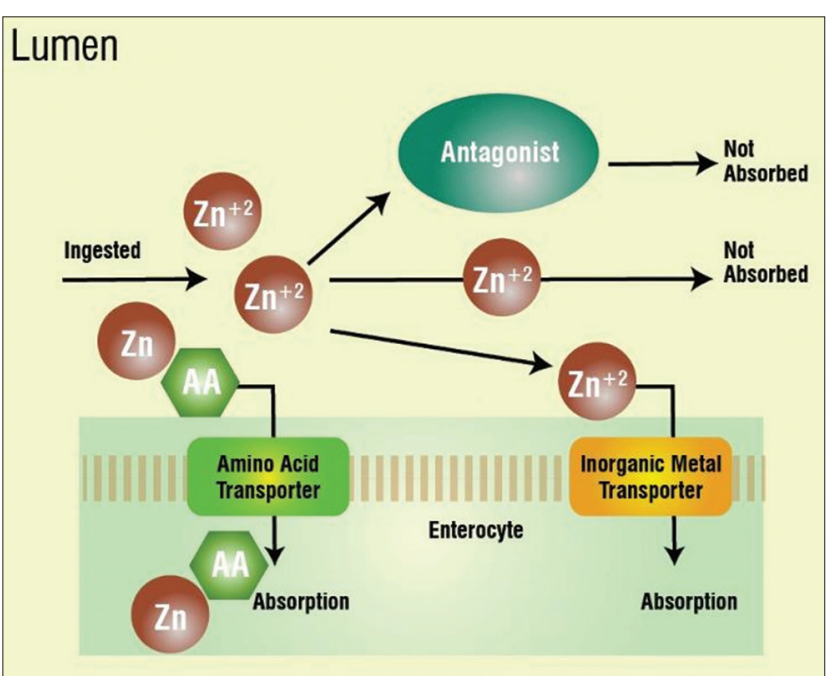

Figure-3: The mechanism of absorption of organic minerals. Source: Sheoran [8].

monoterpene hydrocarbons [69,70]. Essential oils possessing antimicrobial activities are mainly due to the presence of oxygenated terpenoids, while some hydrocarbons also exhibit antimicrobial effects. The interactions between these components may lead to antagonistic effects [71-73]. A mixture of essential oils interacts with each other, acting as antagonistic effects. The synergistic and antagonistic properties of PFAs are summarized in Table-1 [74-81].

\section{Economic Importance of PFAs in Poultry Industry}

Literature reveals that supplementation of PFAs is economical to the poultry industry. Various researchers report that the addition of turmeric powder at $0.5 \%$ in broiler diets significantly decreases the feed cost per unit live body weight gain (by $13.5 \%$ [82], $11.8 \%$ [83], and $6.2 \%$ [84] compared with the respective control diets). The addition of a combination of Aloe vera and Curcuma longa in broiler diet caused a significant difference in the feed cost per unit live body weight [85]. Furthermore, supplementation of a combination of amla, tulasi, and turmeric at a $0.25 \%$ dose along with a commercial broiler diet caused a 4\% reduction in feed cost per unit live body weight gain in broilers [86].
To summarize, organically complexed minerals have many advantages over inorganic sources, such as improved absorption and efficacy that meet the bird's requirements comfortably with low-dose levels. Consequently, it can be recommended that low dietary levels of organic minerals be replaced with inorganic forms without any negative influence on broilers' growth performance and egg production in layers.

Medicinal herbs have proven to be valuable therapeutic aids for humans, animals, and birds since times immemorial. These herbs provide therapeutic relief and are often a safe alternative to conventional treatment and for boosting immune functions. Herbs can also effectively complement conventional medicines in disease management. The global trend in the poultry industry reveals a huge demand for poultry products. Thus, the poultry industry is facing production and bird health-related challenges. For a safe, sustainable, and profitable scenario, alternative remedies to conventional treatments have to be chosen. The practical implementations of PFAs are possible with the recent advancements in science and technology.

\section{Conclusion}

Since organically complexed minerals have many advantages over inorganic sources, PFAs have multiple beneficial applications, and there is a resurgence to develop a cocktail of organic minerals and PFAs to improve the overall health status of birds and augment poultry birds' productivity, which, in turn, helps the poultry industry to grow decisively and economically.

\section{Authors' Contributions}

VGB contributed to the original draft and conception of the specific review. EB contributed to the review, editing, and supported in supervision. VGB and PR worked on the final approval of the version to be published. All authors read and approved the final manuscript.

\section{Acknowledgments}

The authors acknowledge the editorial support provided by Dr. Jayashree B. Keshav and the Team, Scientific Publications Division, The Himalaya Drug 
Company, Bengaluru, Karnataka. The authors did not receive any funds for this study.

\section{Competing Interests} interests.

The authors declare that they have no competing

\section{Publisher's Note}

Veterinary World remains neutral with regard to jurisdictional claims in published institutional affiliation.

\section{References}

1. National Research Council. (1994) Nutrient Requirements of Poultry. $9^{\text {th }}$ ed. The National Academies Press, Washington, DC.

2. Ghosh, A., Mandal, G.P., Roy, A. and Patra, A.K. (2016) Effects of supplementation of manganese with or without phytase on growth performance, carcass traits, muscle and tibia composition, and immunity in broiler chickens. Livest. Sci., 191: 80-85.

3. De Marco, M., Zoon, M.V., Margetyal, C., Picart, C. and Ionescu, C. (2017) Dietary administration of glycine complexed trace minerals can improve performance and slaughter yield in broilers and reduces mineral excretion. Anim. Feed Sci. Technol., 232: 182-189.

4. Mwangi, S., Timmons, J., Ao, T., Paul, M., Macalintal, L., Pescatore, A., Cantor, A., Ford, M. and Dawson, K.A. (2017) Effect of zinc imprinting and replacing inorganic zinc with organic zinc on early performance of broiler chicks. Poult. Sci., 96(4): 861-868.

5. Bao, Y.M., Choct, M., Iji, P.A. and Bruerton, K. (2007) Effect of organically complexed copper, iron, manganese and zinc on broiler performance, mineral excretion and accumulation in tissues. J. Appl. Poult. Res., 16(3): 448-455.

6. Bao, Y.M. and Choct, M. (2009) Trace mineral nutrition for broiler chickens and prospects of application of organically complexed trace minerals: A review. Anim. Prod. Sci., 49(4): 269-282.

7. Pacheco, B.H., Nakagi, V.S., Kobashigawa, E.H., Caniatto, A.R., Faria, D.E. and Filho, D.E.F. (2017) Dietary levels of zinc and manganese on the performance of broilers between 1 to 42 days of age. Braz. J. Poult. Sci., 9(2): 171-178.

8. Sheoran, V.N. (2017) Organic minerals in poultry. $A d v$. Res., 12(3): 1-10.

9. Lopes, M., Paroul, N., Barbosa, J., Valduga, E., Cansian, R.L., Toniazzo, G. and Oliveira, D. (2017) Effect of partial and total replacement of inorganic by organic microminerals sources on the quality of broiler carcasses. Braz. Arch. Biol. Technol., 60: 1-11.

10. Valenzuela-Grijalva, N.V., Pinelli-Saavedra, A., MuhliaAlmazan, A., Domínguez-Díaz, D. and González-Ríos, H. (2017) Dietary inclusion effects of phytochemicals as growth promoters in animal production. J. Anim. Sci. Technol., 59(1): 8 .

11. Chen, S.L., Yu, H., Luo, H.M., Wu, Q., Li, C.F. and Steinmetz, A. (2016) Conservation and sustainable use of medicinal plants: Problems, progress, and prospects. Chin. Med., 11(1): 37.

12. Banumathi, B., Vaseeharan, B., Rajasekar, P., Prabhu, N.M., Ramasamy, P., Murugan, K., Canale, A. and Benelli, G. (2017) Exploitation of chemical, herbal and nanoformulated acaricides to control the cattle tick, Rhipicephalus (Boophilus) microplus-a review. Vet. Parasitol., 244: 102-110.

13. Alloui, M.N., Szczurek, W. and Świątkiewicz, S. (2013) The usefulness of prebiotics and probiotics in modern poultry nutrition: A review. Ann. Anim. Sci., 13(1): 17-32.
14. Yenice, E., Mizrak, C., Gultekin, M., Zafer, A.T. and Tunca, M. (2015) Effects of dietary organic or inorganic manganese, zinc, copper and chrome supplementation on the performance, egg quality and hatching characteristics of laying breeder hens. Ankara Üniv. Vet. Fak. Derg., 62(1): 63-68.

15. Rao, S.R., Prakash, B., Raju, M.V., Panda, A.K., Kumari, R.K. and Reddy, E.P. (2016) Effect of supplementing organic forms of zinc, selenium and chromium on performance, antioxidant and immune responses in broiler chicken reared in tropical summer. Biol. Trace Elem. Res., 172(2): 511-520.

16. Mohammed, H.H., El-Sayed, B.M., Abd El-Razik, W.M., Ali, M.A. and Abd El-Aziz, R.M. (2014) The influence of chromium sources on growth performance, economic efficiency, some maintenance behaviour, blood metabolites and carcass traits in broiler chickens. Glob. Vet., 12(5): 599-605.

17. Gayathri, S.L. and Panda, N. (2018) Chelated minerals and its effect on animal production: A review. Agric. Rev., 39(4): 314-320.

18. Meshreky, S.Z., Allam, S.M., El-Manilawi, M.A. and Amin, H.F. (2015) Effect of dietary supplemental zinc source and level on growth performance, digestibility coefficients and immune response of New Zealand white rabbits. Egypt. J. Nutr. Feeds, 18(2 Special): 383-390.

19. Habibian, M., Sadeghi, G., Ghazi, S. and Moeini, M.M. (2015) Selenium as a feed supplement for heat-stressed poultry: A review. Biol. Trace Elem. Res., 165(2): 183-193.

20. Majewska, D., Szczerbińska, D., Ligocki, M., Bucław, M., Sammel, A., Tarasewicz, Z., Romaniszyn, K. and Majewski, J. (2016) Comparison of the mineral and fatty acid profiles of ostrich, turkey and broiler chicken livers. $\mathrm{Br}$. Poult. Sci., 57(2): 193-200.

21. Aksu, T., Özsoy, B., Aksu, D.S., Yörük, M.A. and Gül, M. (2011) The effects of lower levels of organically complexed zinc, copper and manganese in broiler diets on performance, mineral concentration of tibia and mineral excretion. Kafkas Univ. Vet. Fak. Derg., 17(1): 141-146.

22. Jiang, H., Wang, Z., Ma, Y., Qu, Y., Lu, X. and Luo, H. (2015) Effects of dietary lycopene supplementation on plasma lipid profile, lipid peroxidation and antioxidant defense system in feedlot Bamei lamb. Asian Australas. $J$. Anim. Sci., 28(7): 958-965.

23. Aksu, T., Aksu, M.I. and Yoruk, M.A. (2011) Effects of organically-complexed minerals on meat quality in chickens. Br. Poult. Sci., 52(5): 558-563.

24. Mohammadi, V., Ghazanfari, S., MohammadiSangcheshmeh, A., Nazaran, M.H. (2015) Comparative effects of zinc-nano complexes, zinc-sulphate and zinc-methionine on performance in broiler chickens. Br. Poult. Sci., 56(4): 486-493.

25. Nagalakshmi, D., Sridhar, K. and Parashuramulu, S. (2015) Replacement of inorganic zinc with lower levels of organic zinc (zinc nicotinate) on performance, hematological and serum biochemical constituents, antioxidants status, and immune responses in rats. Vet. World, 8(9): 1156-1162.

26. Byarugaba, D.K. (2020) Poultry Sector Country Review. Available from: http://www.fao.org/3/a-ai378e.pdf. Retrieved on 04-12-2020.

27. Scanes, C.G. (2007) The global importance of poultry. Poult. Sci., 86(6): 1057-1058.

28. Hashemi, S.R. and Davoodi, H. (2012) Herbal plants as new immuno-stimulator in poultry industry: A review. Asian $J$. Anim. Vet. Adv., 7(2): 105-116.

29. Mirzaei-Aghsaghali, A. (2012) Importance of medical herbs in animal feeding: A review. Ann. Biol. Res., 3(2): 918-923.

30. Abiala, M., Olayiwola, J., Babatunde, O., Aiyelaagbe, O. and Akinyemi, S. (2016) Evaluation of therapeutic potentials of plant extracts against poultry bacteria threatening public health. BMC Complement. Altern. Med., 16(1): 417.

31. Umashanker, M. and Shruti, S. (2011) Traditional Indian herbal medicine used as antipyretic, antiulcer, anti-diabetic 
and anticancer: A review. Int. J. Res. Pharm. Chem., 1(4): 1152-1159.

32. Abd El-Hack, M., Alagawany, M., Farag, M.R., Tiwari, R., Karthik, K., Dhama, K., Zorriehzahra, J. and Adel, M. (2016) Beneficial impacts of thymol essential oil on health and production of animals, fish and poultry: A review. $J$. Essent. Oil Res., 28(5): 365-382.

33. Khan, R.U., Naz, S., Nikousefat, Z., Tufarelli, V., Javdani, M., Qureshi, M.S. and Laudadio, V. (2012) Potential applications of ginger (Zingiber officinale) in poultry diets. Worlds Poult. Sci. J., 68(2): 245-252.

34. Khan, R.U., Nikousefat, Z., Tufarelli, V., Naz, S., Javdani, M. and Laudadio, V. (2012) Effect of garlic supplementation in poultry diets. Worlds Poult. Sci. J., 68(3): 417-424.

35. Sridhar, M., Suganthi, R.U. and Thammiaha, V. (2015) Effect of dietary resveratrol in ameliorating aflatoxin B1induced changes in broiler birds. J. Anim. Physiol. Anim. Nutr., 99(6): 1094-1104.

36. Eevuri, T.R. and Putturu, R. (2013) Use of certain herbal preparations in broiler feeds a review. Vet. World, 6(3): 172-179.

37. Panda, A.K. (2008) Growth Promoters in Poultry: Novel Concepts. IBDC Publishers, Lucknow, India. p134.

38. Daramola, O.T. (2019) Medicinal plants leaf meal supplementation in broiler chicken diet: Effects on performance characteristics, serum metabolite and antioxidant status. Anim. Res. Int., 16(2): 3334-3342.

39. Bölükbaş1, S.C. and Erhan, M.K. (2007) Effect of dietary thyme on laying hen's performance and $E$ coli concentration in feces. Int. J. Nat. Eng. Sci., 1(2): 55-58.

40. Windisch, W., Schedle, K., Plitzner, C. and Kroismayr, A. (2008) Use of phytogenic products as feed additives for swine and poultry. J. Anim. Sci., 86(14 Suppl): E140-E148.

41. Dalkiliç, B. and Güler, T. (2009) The effects of clove extract supplementation on performance and digestibility of nutrients in broilers. FU Sag. Bil. Vet. Derg., 23(3): 161-166.

42. Bozkurt, M., Küçükyilmaz, K., Pamukçu, M., Çabuk, M., Alçiçek, A. and Çatli, A.U. (2012) Long-term effects of dietary supplementation with an essential oil mixture on the growth and laying performance of two-layer strains. Ital. $J$. Anim. Sci., 11(1): e5.

43. Steiner, T. (2009) Application and benefits of phytogenics in egg production. In: Phytogenics in Animal Nutrition: Natural Concepts to Optimize Gut Health and Performance. Nottingham University Press, Nottingham, United Kingdom. p157-167.

44. Wallace, R.J., Oleszek, W., Franz, C., Hahn, I., Baser, K.H., Mathe, A. and Teichmann, K. (2010) Dietary plant bioactives for poultry health and productivity. Br. Poult. Sci., 51(4): 461-487.

45. Hashemi, S.R. and Davoodi, H. (2010) Phytogenics as new class of feed additive in poultry industry. J. Anim. Vet. Adv., 9(17): 2295-2304.

46. Christaki, E. (2012) Naturally derived antioxidants in poultry nutrition. Res. J. Biotechnol., 7(3): 109-112.

47. Shahidi, F. and Ambigaipalan, P. (2015) Phenolics and polyphenolics in foods, beverages and spices: Antioxidant activity and health effects a review. J. Funct. Foods, 18(Part B): 820-897.

48. Botsoglou, N.A., Florou-Paneri, P., Christaki, E., Fletouris, D.J. and Spais, A.B. (2002) Effect of dietary oregano essential oil on performance of chickens and on iron-induced lipid oxidation of breast, thigh and abdominal fat tissues. Br. Poult. Sci., 43(2): 223-230.

49. Zeng, Z., Zhang, S., Wang, H. and Piao, X. (2015) Essential oil and aromatic plants as feed additives in non-ruminant nutrition: A review. J. Anim. Sci. Biotechnol., 6(1): 7.

50. Cayan, H. and Erener, G. (2015) Effect of olive leaf (Olea europaea) powder on laying hens performance, egg quality and egg yolk cholesterol levels. Asian Australas. J. Anim. Sci., 28(4): 538-543.
51. Rahal, A., Mahima, V.A., Kumar, A., Tiwari, R., Kapoor, S., Chakraborty, S. and Dhama, K. (2014) Phytonutrients and nutraceuticals in vegetables and their multi-dimensional medicinal and health benefits for humans and their companion animals: A review. J. Biol. Sci., 14(1): 1-19.

52. Ganesan, K., Jayachandran, M. and Xu, B. (2018) A critical review on hepatoprotective effects of bioactive food components. Crit. Rev. Food Sci. Nutr., 58(7): 1165-1229.

53. Wildman, R.E. (2016) Handbook of Nutraceuticals and Functional Foods. CRC Press, Boca Raton, Florida.

54. Deshpande, R.R. (2006) Effect of Dietary Supplementation of Tulsi Leaf Powder (Ocimum sanctum) on Egg Yolk Cholesterol and Serum lipid Profile in Commercial Layers, MAFSU, Nagpur, India.

55. Emadi, M. and Kermanshahi, H. (2007) Effect of turmeric rhizome powder on the activity of some blood enzymes in broiler chickens. Int. J. Poult. Sci., 6(1): 48-51.

56. Prakash, A., Singh, S.P. and Varma, R. (2009) Ameliorative efficacy of tulsi in lead toxicity in cockerels. Indian Vet. J., 86: 344-346.

57. Sapcota, D. and Upadhyaya, T.N. (2009) Efficacy of dietary Ocimum sanctum against aflatoxin B1 in broilers. Indian Vet. J., 86(11): 1163-1165.

58. Lanjewar, R.D., Zanzad, A.A., Ramteke, B.N. and Deshmukh, G.B. (2008) Effect of dietary supplementation of tulsi $(O$. sanctum) leaf powder on the growth performance and serum lipid profile in broilers. Indian J. Anim. Nutr., 25(4): 395-397.

59. Gupta, G. and Charan, S. (2007) Exploring the potentials of Ocimum sanctum (Shyama tulsi) as a feed supplement for its growth promoter activity in broiler chickens. Indian $J$. Poult. Sci., 42(2): 140-143.

60. Joshi, S.S., Ingle, P.B., Bhagwat, S.R., Pawar, M.M., Prajapati, K.B. and Kulkarni, R.C. (2015) Effect of dietary addition of ashwagandha (Withania somnifera) and guduchi (Tinospora cordifolia) powder on broiler performance. Indian J. Anim. Sci., 85(12): 1358-1361.

61. Singh, V.V., Singh, V.K., Tewari, D., Gautam, S., Singh, V.B. and Singh, P. (2019) Performance of broiler chicken fed diets supplemented with a phytogenic mixture. Indian $J$. Anim. Nutr., 36(1): 58-64

62. Ren, H., Vahjen, W., Dadi, T., Saliu, E.M., Boroojeni, F.G. and Zentek, J. (2019) Synergistic effects of probiotics and phytobiotics on the intestinal microbiota in young broiler chicken. Microorganisms, 7(12): 684.

63. Upadhaya, S.D. and Kim, I.H. (2017) Efficacy of phytogenic feed additive on performance, production and health status of monogastric animals-a review. Ann. Anim. Sci., 17(4): 929-948.

64. Ahmed, M., Henson, D.A., Sanderson, M.C., Nieman, D.C., Zubeldia, J.M. and Shanely, R.A. (2015) Rhodiola rosea exerts antiviral activity in athletes following a competitive marathon race. Front. Nutr., 31(2): 24.

65. Suryakumar, G. and Gupta, A. (2011) Medicinal and therapeutic potential of Sea buckthorn (Hippophae rhamnoides L.). J. Ethnopharmacol., 138(2): 268-278.

66. Hernandez, F., Madrid, J., Garcia, V., Orengo, J. and Megias, M.D. (2004) Influence of two plant extracts on broilers performance, digestibility, and digestive organ size. Poult. Sci., 83(2): 169-174.

67. Bakkali, F., Averbeck, S., Averbeck, D. and Idaomar, M. (2008) Biological effects of essential oils-a review. Food Chem. Toxicol., 46(2): 446-475.

68. Lin, Y.T., Kwon, Y.I., Labbe, R.G. and Shetty, K. (2005) Inhibition of Helicobacter pylori and associated urease by oregano and cranberry phytochemical synergies. Appl. Environ. Microbiol., 71(12): 8558-8564.

69. Hammer, K.A., Carson, C.F. and Riley, T.V. (1999) Antimicrobial activity of essential oils and other plant extracts. J. Appl. Microbiol., 86(6): 985-990.

70. Goni, P., López, P., Sánchez, C., Gómez-Lus, R., Becerril, R. and Nerín, C. (2009) Antimicrobial activity in 
the vapour phase of a combination of cinnamon and clove essential oils. Food Chem., 116(4): 982-989.

71. Delaquis, P.J., Stanich, K., Girard, B. and Mazza, G. (2002) Antimicrobial activity of individual and mixed fractions of dill, cilantro, coriander and eucalyptus essential oils. Int. J. Food Microbiol., 74(1-2): 101-109.

72. Gill, A.O., Delaquis, P., Russo, P. and Holley, R.A. (2002) Evaluation of antilisterial action of cilantro oil on vacuum packed ham. Int. J. Food Microbiol., 73(1): 83-92.

73. Mourey, A. and Canillac, N. (2002) Anti-Listeria monocytogenes activity of essential oils components of conifers. Food Control, 13(4-5): 289-292.

74. Pei, R.S., Zhou, F., Ji, B.P. and Xu, J. (2009) Evaluation of combined antibacterial effects of eugenol, cinnamaldehyde, thymol, and carvacrol against $E$. coli with an improved method. J. Food Sci., 74(7): 379-383.

75. Gallucci, M.N., Oliva, M., Casero, C., Dambolena, J., Luna, A., Zygadlo, J. and Demo, M. (2009) Antimicrobial combined action of terpenes against the food-borne microorganisms Escherichia coli, Staphylococcus aureus and Bacillus cereus. Flav. Fragr. J., 24(6): 348-354.

76. Vuuren, S.V. and Viljoen, A.M. (2007) Antimicrobial activity of limonene enantiomers and 1,8-cineole alone and in combination. Flav. Fragr. J., 22(6): 540-544.

77. Tserennadmid, R., Takó, M., Galgóczy, L., Papp, T., Pesti, M., Vágvölgyi, C., Almássy, K. and Krisch, J. (2011) Anti yeast activities of some essential oils in growth medium, fruit juices and milk. Int. J. Food Microbiol., 144(3): 480-486.

78. De Azeredo, G.A., Stamford, T.L., Nunes, P.C., Neto, N.J., De Oliveira, M.E. and De Souza, E.L. (2011) Combined application of essential oils from Origanum vulgare L. and Rosmarinus officinalis L. to inhibit bacteria and autochthonous microflora associated with minimally processed vegetables. Food Res. Int., 44(5): 1541-1548.

79. Bassolé, I.H., Lamien-Meda, A., Bayala, B., Tirogo, S., Franz, C., Novak, J., Nebié, R.C. and Dicko, M.H. (2010)
Composition and antimicrobial activities of Lippia multiflora Moldenke, Mentha x piperita L. and Ocimum basilicum L. essential oils and their major monoterpene alcohols alone and in combination. Molecules, 15(11): 7825-7839.

80. Fu, Y., Zu, Y., Chen, L., Shi, X., Wang, Z., Sun, S. and Efferth, T. (2007) Antimicrobial activity of clove and rosemary essential oils alone and in combination. Phytother. Res., 21(10): 989-994.

81. Bassolé, I.H., Lamien-Meda, A., Bayala, B.O., Obame, L.C., Ilboudo, A.J., Franz, C., Novak, J., Nebié, R.C. and Dicko, M.H. (2011) Chemical composition and antimicrobial activity of Cymbopogon citratus and Cymbopogon giganteus essential oils alone and in combination. Phytomedicine, 18(12): 1070-1074.

82. Manish, K., Choudhary, R.S. and Vaishnav, J.K. (2005) Effect of supplemental prebiotic, probiotic and turmeric in diet on the performance of broiler chicks during summer. Indian J. Poult. Sci., 40(2): 137-141.

83. Durrani, F.R., Ismail, M., Sultan, A., Suhail, S.M., Chand, N. and Durrani, Z. (2006) Effect of different levels of feed added turmeric (Curcuma longa) on the performance of broiler chicks. Am. J. Agric. Biol. Sci., 1(2): 9-11.

84. Mondal, M.A., Yeasmin, T., Karim, R., Siddiqui, M.N., Nabi, S.R., Sayed, M.A. and Siddiky, M.N. (2015) Effect of dietary supplementation of turmeric (Curcuma longa) powder on the growth performance and carcass traits of broiler chicks. SAARC J. Agric., 13(1): 188-199.

85. Shokri, A.N., Ghasemi, H.A. and Taherpour, K. (2017) Evaluation of Aloe vera and synbiotic as antibiotic growth promoter substitutions on performance, gut morphology, immune responses and blood constitutes of broiler chickens. Anim. Sci. J., 88(2): 306-313.

86. Krishna, D., Srinivas, G., Vijay, K. and Swathi, B. (2018) Efficacy of herbal immunomodulator and antistressor products on the performance and cost economics of broilers during summer stress. Indian J. Poult. Sci., 53(1): 49-53. 